\title{
Uteroplacental Blood Flow and Uteroplacental Shunt Rates in Normal and Prolonged Pregnancies in Rats
}

\author{
Ryuji Yamaguchi, Masafumi Shintani, Shobu Ishibashi, \\ Etsuo Ushioda and Yoshio Nishikawa \\ Department of Obstetrics and Gynecology, Nara Medical \\ Uviversity, Kashihara 634
}

\begin{abstract}
Yamaguchi, R., Shintani, M., Ishibashi, S., Ushioda, E. and Nishrikawa, Y. Uteroplacental Blood Flow and Uteroplacental Shunt Rates in Normal and Prolonged Pregnancies in Rats. Tohoku J. exp. Med., 1979, 127 (4), 389-396 - To reveal the regulatory function in uteroplacental blood flow we measured, using the method of double tracer microspheres, the rates of uteroplacental blood flow (UPBF) and uteroplacental shunt (UP-shunt) in SD-strain rats of normal and prolonged pregnancy. (1) In the group of rats of normal pregnancy, the rate of UPBF attained a peak on the 20th day of gestation, while the UP-shunt rate was highest on the 18th day of gestation. (2) In the progesterone-induced prolonged pregnancy group, the rate of UPBF remained at an $8 \%$ level until the $22 \mathrm{nd}$ day, i.e., the first day of prolonged pregnancy, and dropped to $6.6 \%$ on the 23rd day. The UP-shunt rate in the progesterone-administered group was about $27 \%$ on the 20 th day, more favorable than the corresponding rate in the normal group, but thereafter rapidly decreased. The rate of increase in fetal body weight in this group became lower, showing a fetal death rate of $4.6 \%$. (3) The decreases in placental alkaline phosphatase and leucine aminopeptidase examined as markers of placental function lagged behind the fall in the UP-shunt rate. On the 23rd day of gestation when the rates of UPBF and UP-shunt dropped, the decreases in their placental enzyme activities were remarkable.

UPBF; UP-shunt rate; prolonged pregnancy
\end{abstract}

As for the uteroplacental blood circulation, particularly uteroplacental blood flow (UPBF), the basic factor for maintaining placental function, human and animal data have been presented in several reports. Still there remain many problems yet to be solved mainly originating in the difficulty of experimental tracing which has left investigations virtually untouched on the hemodynamic changes throughout the progress of gestation, or under the non-anesthetized, non-restraint condition. Although the existence of a shunt in the uteroplacental circulation system was suggested by Metcalfe et al. (1953), its role in the intrauterine fetal growth has not yet been elucidated. In the present study, using our double

Received for publication, June 9, 1978.

Supported by Grant No. 148267 from the Ministry of Education, Science and Culture, Japan.

Reprint request: Dr. Ryuji Yamaguchi, Department of Obstetrics and Gynecology, Nara Medical University, Kashihara, Nara 634, Japan. 
tracer microspheres method (double TMS method), we measured the rates of uteroplacental blood flow and uteroplacental shunt in rats of normal and prolonged pregnancies to pursue these rates' relations to the fetal growth and placental function.

\section{Methods}

\section{Normal pregnancy}

Used for the experiment were rats of the Sprague-Dawley strain, weighing 180-210 g. A female rat was let to live with a male rat after 6 p.m. Vaginal plug or intra-vaginal sperm confirmed in the next morning $(10$ a.m.) was served to decide the day as the 0 day of gestation. Most of impregnated rats came to parturition on the morning, some on the afternoon, of the 21 st day of gestation.

\section{Prolonged pregnancy}

Following the method of Vorherr (1975), prolonged pregnancy was produced by intramuscular injection of free-type progesterone, $5 \mathrm{mg}$, into the mother rat for three consecutive days from the 18th day. This procedure could elongate pregnancy in the rat up to 23 or longer days, but the experiments were performed on the 23rd day's rats. Blood pressure in this group of rats slightly rose to some $120 \mathrm{mmHg}$. By way of comparison for placental function, the placental enzyme activities were determined on alkaline phosphatase and leucine aminopeptidase.

\section{Measurement of rates of UPBF and UP-shunt}

Catheter insertion. Following the method of Popovic et al. (Popovic and Popovic 1960; Popovic et al. 1963), Sasaki and Wagner (1971) and Yamaguchi et al. (1975), a tube for epidural anesthesia, $1 \mathrm{~mm}$ in external diameter, was inserted from the right common carotid artery of the ether-anesthetized rat and its tip was led to reach the left ventriele. Whether the catheter reached the left ventricle or not was finally concluded after the rat was sacrificed for the experiment. The catheter-bearing rat recovered from anesthesia 2 to 3 min later and vigorously moved.

Infusion of tracer microspheres and determination of radioactivity. In the present experiment, two kinds of carbonized plastic microspheres (Minnesota Mining \& Manufacturing Co.), ${ }^{85} \mathrm{Sr}(\phi 50 \pm 10 \mu \mathrm{m})$ and ${ }^{51} \mathrm{Cr}(\phi 25 \pm 5 \mu \mathrm{m})$, were used. These, at a rate of $1 \mathrm{mCi} / 10 \mathrm{ml}$, were led to suspend in a $10 \%$ dextran solution, with a drop of Tween 20 added to make the mixture homogeneous.

After the rat was completely recovered from anesthesia, a TMS-containing glass tube was connected with the dorsally fixed catheter and into it was flushed the TMS with physiological saline. After the rat was slaughtered, each relevant organ was taken out and weighed, and its radioactivity was determined using an autogamma scintillation counter (Packard-3150) through a double-window procedure, and the difference of energy peaks between ${ }^{85} \mathrm{Sr}$ and ${ }^{51} \mathrm{Cr}$ was used to indicate the individual level of radioactivity emitted in each rat (Fig. 1). The radioactivity remaining in the glass tube after TMS infusion was also determined to identify the percentage of the share in each organ to total of radioactivity impregnated. In line with Forsyth et al. (1968), the case showing more than $15 \%$ in the difference of radioactivity between the left and right kidneys was excluded as the instance of technical error.

\section{Determination of alkaline phosphatase and leucine aminopeptidase}

Alkaline phosphatase (AP) and leucine aminopeptidase (LAP) in the placenta were determined to serve as markers for placental function. In another group of pregnant rats, the uterus was resected inclusive of the placenta and fetuses on a scheduled day of gestation. 


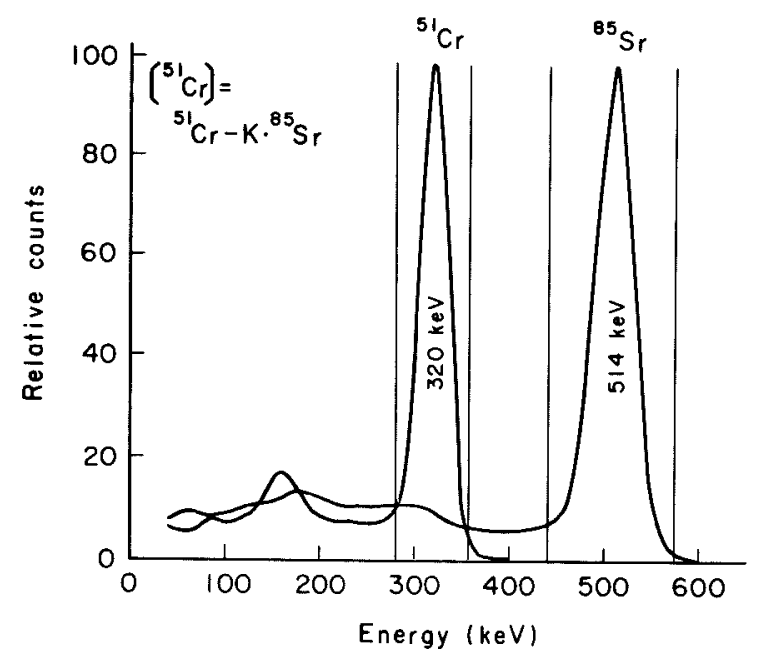

Fig. 1. Measurement of radioactivity by double-window method.

${ }^{51} \mathrm{Cr}$, counted radioactivity; [ $\left.{ }^{51} \mathrm{Cr}\right]$, corrected radioactivity by constant $K$.

The placenta was separated into the fetal and the maternal side and each was put in a $10 \%$ PBS (-) solution for homogenization. After that, the homogenate was centrifuged for 60 min at $18,000 \mathrm{rpm}$. The supernatant was scooped up for determination of AP and LAP using commercial kits for AP and LAP (Ishizu Chem. Co.). The values were expressed in the unit of $\mu \mathrm{mole} / \mathrm{min} / \mathrm{mg}$ protein. Protein was quantitated by the biuret method.

\section{Results}

\section{Preliminary experiments to confirm the presence of UP-shunt}

Following the method of Yamaguchi et al. (1976), ${ }^{85} \mathrm{Sr}(50 \mu \mathrm{m})$ and ${ }^{51} \mathrm{Cr} \quad(25$ $\mu \mathrm{m})$ were rapidly injected into the abdominal aorta just below the renal artery. After that, the rats were killed and the lungs were taken out to determine their emitting radioactivity. A significant level of radioactivity was counted only in the lung of the pregnant rat, in which $25 \mu \mathrm{m}$ TMS was detected, demonstrating that some shunt vessels existing below the renal artery had functioned for $25 \mu \mathrm{m}$ but not for $50 \mu \mathrm{m}$ particles to pass through them. No such phenomenon was observed in the non-pregnant rat. The findings have convinced us to conclude that the uteroplacental circulation system has shunt vessels acting to meet physiological requirements.

Changes in rate of UPBF and UP-shunt with progress of pregnancy in normal rats

$U P B F$. The results are illustrated in Fig. 2. In non-pregnancy, the rat had a blood distribution of $0.5 \%$ of cardiac output to the uterus for both ${ }^{85} \mathrm{Sr}(50 \mu \mathrm{m})$ and ${ }^{51} \mathrm{Cr}(25 \mu \mathrm{m})$. But as pregnancy progressed, UPBF increased showing rates of $2.0 \%(50 \mu \mathrm{m})$ and $1.9 \%(25 \mu \mathrm{m})$ on the 11 th day of gestation, $5.2 \%(50 \mu \mathrm{m})$ and $4.2 \%(25 \mu \mathrm{m})$ on the 18th day, further rapidly increasing to reveal peaks of $12.0 \%(50 \mu \mathrm{m})$ and $9.9 \%(25 \mu \mathrm{m})$ on the 20 th day. The rates dropped to $8.9 \%$ 


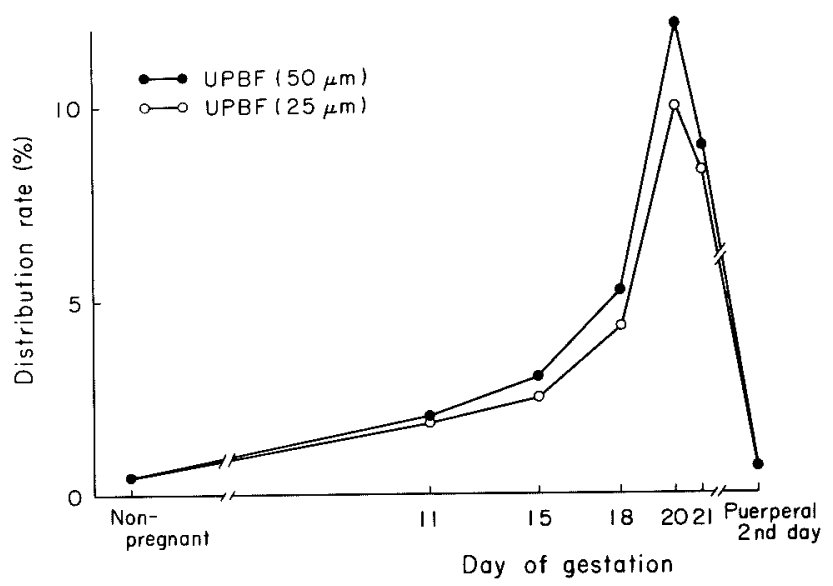

Fig. 2. UPBF in normal pregnant rats measured with ${ }^{85} \mathrm{Sr}(50 \mu \mathrm{m})$ and ${ }^{51} \mathrm{Cr}(25 \mu \mathrm{m})$.

$(50 \mu \mathrm{m})$ and $8.3 \%(25 \mu \mathrm{m})$ on the 21 st day, the expected date of confinement. On the puerperal 2 nd day, the rate sharply dropped to $0.7 \%$ for both $50 \mu \mathrm{m}$ and $25 \mu \mathrm{m}$ TMS (Table 1, Fig. 2). In these experiments, the value of $25 \mu \mathrm{m}$ TMS in each case did never exceed the value of $50 \mu \mathrm{m}$. As the difference between $50 \mu \mathrm{m}$ and $25 \mu \mathrm{m}$ values seemed to indicate the particles having passed through the UP-shunt, the value of $50 \mu \mathrm{m}$ was taken to represent UPBF itself.

UP-shunt rate. The UP-shunt rate was obtained applying following expressions:

$$
\text { UP-shunt rate }(\%)=\frac{(\mathrm{UPBF} \text { in } 50 \mu \mathrm{m})-(\mathrm{UPBF} \text { in } 25 \mu \mathrm{m})}{(\mathrm{UPBF} \text { in } 50 \mu \mathrm{m})} \times 100 \text {. }
$$

The rate of UP-shunt, $0 \%$ in non-pregnant state, increased with progress of pregnancy, rising to $15.3 \%$ on the 15 th day of gestation and to its peak $18.9 \%$ on

TABLE 1. UPBF and UP-shunt rate measured by the double TMS method in normal and progesterone-induced prolonged pregnancies in rats

\begin{tabular}{|c|c|c|c|c|c|}
\hline & & $\begin{array}{l}\text { Number } \\
\text { of rats }\end{array}$ & $\mathrm{UPBF}$ in $50 \mu \mathrm{m}$ & $\mathrm{UPBF}$ in $25 \mu \mathrm{m}$ & UP-shunt rate \\
\hline \multicolumn{2}{|c|}{ Non-pregnant state } & 6 & $0.5 \pm 0.11$ & $0.5 \pm 0.11$ & 0.0 \\
\hline $\begin{array}{l}\text { Normal } \\
\text { pregnacy }\end{array}$ & $\begin{array}{l}\text { llth day } \\
\text { 15th day } \\
\text { 18th day } \\
\text { 20th day } \\
21 \text { st day }\end{array}$ & $\begin{array}{l}6 \\
5 \\
5 \\
5 \\
4\end{array}$ & $\begin{array}{c}2.0 \pm 0.19 \\
3.0 \pm 1.13 \\
5.2 \pm 0.79 \\
12.0 \pm 1.08(1) \\
8.9 \pm 2.53\end{array}$ & $\begin{array}{l}1.9 \pm 0.19 \\
2.5 \pm 1.02 \\
4.2 \pm 0.60 \\
9.9 \pm 0.82 \\
8.3 \pm 2.60\end{array}$ & $\begin{array}{r}4.4 \pm 1.75(6) \\
15.3 \pm 1.81(7) \\
18.9 \pm 1.31(8) \\
16.8 \pm 2.23(9) \\
10.5 \pm 3.57(10)\end{array}$ \\
\hline Postpartum 2 & 2nd day & 5 & $0.7 \pm 0.06$ & $0.7 \pm 0.04$ & $4.7 \pm 2.88$ \\
\hline $\begin{array}{l}\text { Progesterone } \\
\text { treated }\end{array}$ & $\begin{array}{l}\text { 20th day } \\
21 \text { st day } \\
22 \text { nd day } \\
23 \text { rd day }\end{array}$ & $\begin{array}{l}5 \\
5 \\
5 \\
5\end{array}$ & $\begin{array}{l}8.6 \pm 1.33(2) \\
8.1 \pm 1.03(3) \\
8.2 \pm 0.53(4) \\
6.6 \pm 1.61(5)\end{array}$ & $\begin{array}{l}6.3 \pm 0.94 \\
6.8 \pm 0.78 \\
7.9 \pm 0.69 \\
6.5 \pm 1.62\end{array}$ & $\begin{array}{r}26.7 \pm 3.19(11) \\
14.4 \pm 2.72(12) \\
4.8 \pm 2.54(13) \\
2.8 \pm 1.07(14)\end{array}$ \\
\hline
\end{tabular}

Mean \pm s.E.

$p<0.01: 1>3,4,5 ; 8>6,13,14 ; 11>10,12,13,14$.

$p<0.05: 1>2 ; 8>10 ; 11>8,9$. 
the 18 th day, then it turned to decrease, showing $16.8 \%$ on the 20 th day, $10.5 \%$ on the 21 st day. The difference between the value on the 18th day and that on the 21 st day was significant $(p<0.01)$. On the puerperal 2 nd day it showed $4.7 \%$ (Table 1).

\section{Rates of UPBF and UP-shunt in prolonged pregnancy}

In the rats of prolonged pregnancy induced by progesterone loading, the rate of UPBF on the 20 th day of gestation was $8.6 \%$, significantly lower than that in the normal group $(p<0.05)$, and kept some $8 \%$ until the 22 nd day. But on the 23rd day it dropped to $6.6 \%(p<0.01)$. The UP-shunt rate in this group was $26.7 \%$ on the 20 th day of gestation, significantly higher than that in the normal 18 th day group $(p<0.01)$, but thereafter precipitously decreased showing $14.4 \%$ on the 21 st day, $4.8 \%$ on the $22 \mathrm{nd}$ day, and $2.8 \%$ on the $23 \mathrm{rd}$ day.

Activity of alkaline phosphatase and leucine aminopeptidase in the placenta

In rats of normal pregnancy, the activity of AP in the fetal side placenta gradually decreased from its peak on the 18th day of gestation until the day of parturition, and thereafter it precipitously fell in the prolonged pregnancy in parallel with the decreases in rate of UPBF and UP-shunt. The activity of LPA in the fetal side placenta, dissimilar to AP's, held a level of the 20th day until the 22nd day, and dropped on the 23rd day. This suggested a dependency of LAP, unlike AP, on progesterone. Nevertheless, decreases in enzyme activity were obvious on the 23rd day, showing general depletion of metabolic activity of the placenta due to 2 days prolongation of pregnancy. In the maternal side placenta, AP showed its activity tending to decline but the change was comparatively indistinct, while LAP showed a trend almost similar to that in the fetal side placenta until the term, but revealed a low value on the 2 nd day of prolonged pregnancy. The behavior of these enzymes with prolonged pregnancy was almost similar to that with the prolonged pregnancy dissimilarly produced by the cervical blocking procedure (Table 2).

TABLE 2. Activities of placental alkaline phosphatase (AP) and leucine aminopeptidase $(L A P)$ in normal and progesterone-induced prolonged pregnancies in rats

\begin{tabular}{|c|c|c|c|c|c|c|}
\hline & \multirow{2}{*}{$\begin{array}{l}\text { Day of } \\
\text { Gestation }\end{array}$} & \multirow{2}{*}{$\begin{array}{l}\text { Number } \\
\text { of dams }\end{array}$} & \multicolumn{2}{|c|}{$\mathrm{AP}(\mu$ moles $/ \mathrm{min} / \mathrm{mg}$ protein $)$} & \multicolumn{2}{|c|}{ LAP ( $\mu$ moles $/ \mathrm{min} / \mathrm{mg}$ protein) } \\
\hline & & & Fetal side & Maternal side & Fetal side & Maternal side \\
\hline \multirow{4}{*}{$\begin{array}{l}\text { Normal } \\
\text { pregnancy }\end{array}$} & 18th & 6 & $905 \pm 105.7$ & $181 \pm 10.6$ & $14.4 \pm 0.85$ & $8.2 \pm 0.69$ \\
\hline & 19th & 7 & $780 \pm 41.1$ & $248 \pm 13.2$ & $17.8 \pm 1.24$ & $12.5 \pm 0.52$ \\
\hline & 20 th & 10 & $576 \pm 37.9$ & $127 \pm 10.1$ & $16.9 \pm 1.10$ & $11.7 \pm 0.79$ \\
\hline & $21 \mathrm{st}$ & 8 & $561 \pm 54.1$ & $149 \pm 11.3$ & $12.0 \pm 1.23$ & $7.9 \pm 0.70$ \\
\hline \multirow{5}{*}{$\begin{array}{l}\text { Prolonged } \\
\text { pregnancy }\end{array}$} & 19 th & 5 & $704 \pm 49.1$ & $185 \pm 14.7$ & $20.0 \pm 0.98$ & $14.4 \pm 0.84$ \\
\hline & $20 \mathrm{th}$ & 7 & $470 \pm 30.6$ & $78 \pm 4.1$ & $17.2 \pm 0.85^{*}$ & $12.2 \pm 0.81^{*}$ \\
\hline & 21 st & 5 & $458 \pm 41.1$ & $85 \pm 3.5$ & $19.5 \pm 1.25$ & $7.7 \pm 0.58$ \\
\hline & $22 \mathrm{nd}$ & 7 & $451 \pm 34.3$ & $87 \pm 6.8$ & $20.2 \pm 1.32$ & $11.5 \pm 0.49$ \\
\hline & $23 \mathrm{rd}$ & 8 & $383 \pm 28.2$ & $82 \pm 27.5$ & $14.5 \pm 1.13$ & $7.1 \pm 0.56$ \\
\hline
\end{tabular}

$* N=6 . \quad \operatorname{Mean} \pm$ s.t. 


\section{Fetal body weight and fetal mortality}

In the group of rats of normal pregnancy, the fetal body weight increased sharply from the 15 th day of gestation, showing $4.04 \mathrm{~g}$ on the 20 th day and $5.15 \mathrm{~g}$ on the term 21 st day. The newborn had a weight of $5.78 \mathrm{~g}$ on the neonatal first day and $6.87 \mathrm{~g}$ on the $2 \mathrm{nd}$ day. The fetal death rate first appeared at $1.31 \%$ on the 21 st day of gestation. In the group of rats of progesterone-induced prolonged pregnancy, the fetal body weight was $3.98 \mathrm{~g}$ on the 20 th day of gestation and increased with days. On the 23rd day, that is, 2nd day of prolonged pregnancy, the weight was $6.52 \mathrm{~g}$, significantly lower than that of normal postnatal 2nd day $(p<0.01)$. The fetal death rate was $4.6 \%$ on the 23 rd day (Table 3).

TABLE 3. Weight and death rates of fetus in normal and progesterone-induced prolonged pregnancies in rats

\begin{tabular}{|c|c|c|c|c|}
\hline & $\begin{array}{l}\text { Gestation } \\
\text { day }\end{array}$ & $\begin{array}{l}\text { Number } \\
\text { of live } \\
\text { fetuses }\end{array}$ & $\begin{array}{l}\text { Number of dead } \\
\text { fetuses }(\%)\end{array}$ & $\begin{array}{c}\text { Weight of live } \\
\text { fetuses (g) } \\
\text { (Mean士s.E.) }\end{array}$ \\
\hline \multirow{6}{*}{$\begin{array}{l}\text { Normal pregnancy } \\
\text { (*After birth) }\end{array}$} & I5th & 59 & 0 & $0.28 \pm 0.005$ \\
\hline & 18th & 99 & 0 & $1.83 \pm 0.032$ \\
\hline & 20 th & 86 & 0 & $4.03 \pm 0.030$ \\
\hline & $21 s t$ & 79 & $1(1.31)(1)$ & $5.15 \pm 0.054(3)$ \\
\hline & $1 s t^{*}$ & 54 & 1 & $5.78 \pm 0.039^{*}$ \\
\hline & $2 n d^{*}$ & 35 & 1 & $6.87 \pm 0.051^{*}(4)$ \\
\hline \multirow{4}{*}{$\begin{array}{l}\text { Progesterone- } \\
\text { treated }\end{array}$} & 20 th & 76 & 0 & $3.98 \pm 0.068$ \\
\hline & 21 st & 104 & 0 & $5.28 \pm 0.035(5)$ \\
\hline & 22 nd & 80 & 0 & $5.91 \pm 0.084$ \\
\hline & 23 rd & 152 & $7(4.61)(2)$ & $6.49 \pm 0.042(6)$ \\
\hline
\end{tabular}

$p<0.01:(2)>(1) ;(4)>(6)$.

$p<0.05:(5)>(3)$.

\section{Discussion}

In measuring the rate of UPBF by means of TMS, various sizes of TMS were used by many authors; $35 \pm 5 \mu \mathrm{m}$ and $50 \pm 10 \mu \mathrm{m}$ by Duncan (1969), $25 \pm 5 \mu \mathrm{m}$ by Swiet and Hoffbrand (1971) and Leduc (1972), $19 \pm 2 \mu \mathrm{m}$ by Ferris et al. (1972), $50 \pm 10 \mu \mathrm{m}$ by Lees et al. (1971), $50 \pm 10 \mu \mathrm{m}, 35 \pm 5 \mu \mathrm{m}$ and $25 \pm 5 \mu \mathrm{m}$ by Makowski et al. (1968). Sasaki and Wagner (1971), using TMS of $50 \pm 10 \mu \mathrm{m}$ in SD-strain male rats, did not detect any resultant re-circulation, nor did Yamaguchi et al. (1975) in their experiments with pregnant rats using TMS of $50 \pm 10 \mu \mathrm{m}$. In the present preliminary experiment with pregnant rats, we used the double TMS method and confirmed the existence of shunt vessels in the uteroplacental circulation system that allow the passage of particles of $25 \pm 5 \mu \mathrm{m}$ but not those of $50 \pm 10 \mu \mathrm{m}$.

Increases in UPBF with progress of pregnancy have been reported in many experiments with medium or large animals, but it was not until 1975 that Yamaguchi et al. (1975), followed by Ushioda et al. (1976), measured the rate of $\mathrm{UPBF}$ in the minor animal pregnant rats with neither anesthesia nor restraint 
throughout the course of gestation. In our present experiment it was found that in normal pregnancy the rate of UPBF attained a peak one day prior to the expected date of confinement, and slightly dropped on the very day of confinement - the 21st day of gestation. The results have substantiated, from the point of UPBF, the general findings that the placental function shows a peak before the term and then decline toward parturition.

On the values of UP-shunt, Makowski et al. (1968), using $25 \pm 5 \mu \mathrm{m}$ TMS in sheep, found a UP-shunt rate of $16 \%$ in the late stage of pregnancy, and Bartels et al. (1972) pointed out about $25 \%$ as a rate of human myometrial-placental shunt. In our present study, the UP-shunt rate of rats was $18.9 \%$ on the 18 th day of gestation, showing no appreciable difference from the figures presented by the two predecessors despite the difference in experimental animal.

It is of deep interest that after the 18th day of gestation, UP-shunt rate decreased against the increase in UPBF. We believe the UP-shunt in the uteroplacental circulation is likely present as a physiological need for the placenta and the fetus. This can be speculated from the fact that in abnormal pregnancies of rats the myometrial share of UPBF precedes the placental share in reduction (Ushioda et al. 1976). The UP-shunt has a special function playing a reserve or regulatory role in maintaining intervillous blood flow necessary for the fetus. Progress of abnormality in pregnancy may lead to exhaustion of the shunt with the resultant failure in maintaining necessary blood flow in the intervillous space, eventually causing SFD and other fetal deprivation. Viewed from the point of placental enzymes, the fact that the decrease in the activity of AP or LAP generally went with the depression in UP-shunt or UPBF seems to suggest that the depression of placental function in prolonged pregnancy is in close relation to the affected uteroplacental blood supply.

In producing prolonged pregnancy, we chose progesterone loading in this study. Our procedure still involves some problems in the analysis of data due to pharmacologic effects of progesterone on the myometrium and the placenta in comparison with other method using chordotomy (Nagai et al. 1972) or paracervical alcohol blocking (Ishibashi et al. 1978). Nonetheless, we adopted it for the reason of its higher rate in producing prolonged pregnancy with a less incidence of fetal death. Even with this mild procedure, UPBF decreased and fetal death rate increased on the 2nd day of prolonged pregnancy. Simply figuring one day of pregnancy for the rat to fit two weeks for the human case, the results of the present experiment incidentally agree with the clinical definition that two weeks over the expected date of confinement is a pathological pregnancy. In view of UPBF, a real prolonged pregnancy in human cases involves a risk to the fetus, needing close attention in induction of labor.

The findings in the present experiments have led us to confirm that the uteroplacental circulation system has shunt vessels which play a significant role in regulating the placental blood flow to maintain placental function and support fetal growth. We have a speculation that these shunt vessels not only close anatomically 
in pathological pregnancy, but perhaps open or close functionally under the physiological condition to adjust the blood supply for the placenta.

\section{References}

1) Bartels, H., Riegel, K., Wenner, J. \& Wolf, H. (1972) Perinale Atmung - Physiologische Grundlagen und therapeutische Konsequenzen. Springer-Verlag, Berlin-New York, pp. 57-59.

2) Duncan, S.L.B. (1969) The partition of uterine blood flow in the pregnant rabbit. J. Physiol., 204, 421-433.

3) Ferris, T.F., Stein, J.H. \& Kauffman, J. (1972) Uterine blood flow and uterine renin secretion. J. clin. Invest., 51, 2827-2833.

4) Forsyth, R.P., Nies, A.S, Wyler, F., Neutze, J. \& Melmon, K.L. (1968) Normal distribution of cardiac output in the unanesthetized, restrained rhesus monkey. $J$. appl. Physiol., 25, 736-741.

5) Ishibashi, S., Moriyama, S.I. \& Yamaguchi, R. (1978) A new method of induction of prolonged pregnancy by paracervical alcohol blocking in rats. Acta obstet. gynaec. jpn., 30, 85-86. (Japanese)

6) Leduc, B. (1972) Maternal placental blood flow and gestational age in rabbits. Amer. J. Obstet. Gynec., 122, 374-378.

7) Lees, M.H., Hill, J.D., Ochsner III, A.J., Thomas, C.L. \& Novy, M.J. (1971) Maternal placental and myometrial blood flow of the rhesus monkey during uterine contractions. Amer. J. Obstet. Gynec., 110, 68-81.

8) Makowski, E.L., Meschia, G., Droegemueller, W. \& Battaglia, F.C. (1968) Distribution of uterine blood flow in the pregnant sheep. Amer. J. Obstet. Gynec., 101, 409-412.

9) Metcalfe, J., Romney, S.L., Ramsey, L.H. \& Reid, D.E. (1953) An approach to the measurement of uterine blood flow in pregnancy. J. clin. Invest., 32, 589-590.

10) Nagai, S., Ichijo, M. \& Numata, A. (1972) Significance of cystine aminopeptidase in obstetrics. Obstet. Gynec. (Tokyo), 39, 1039-1043.

11) Popovic, V. \& Popovic, P. (1960) Permanent canulation of aorta and vena cava in rats and grand squirrels. J. appl. Physiol., 15, 727-728.

12) Popovic, V., Kent, K.M. \& Popovic, P. (1963) Technique of permanent canulation of right ventricle in rats and grand squirrels. Proc. Soc. exp. Biol. Med., 113, 599-602.

13) Sasaki, Y. \& Wagner, H.N. (1971) Measurement of the distribution of cardiac output in unanesthetized rats. J. appl. Physiol., 30, 879-884.

14) Swiet, M. \& Hoffbrand, B.I. (1971) Effect of bethanidine on placental blood flow in conscious rabbits. Amer. J. Obstet. Gynec., 111, 374-378.

15) Ushioda, E., Yamaguchi, R., Nishikawa, Y. \& Shintani, M. (1976) Uteroplacental blood flow in several abnormal pregnancies of rats studied with the microspheres method. Acta obstet. gynaec. jpn., 23, 231-235.

16) Vorherr, H. (1975) Placental insufficiency in relation to postterm pregnancy and fetal postmaturity - Evaluation of fetoplacental function; management of the postterm gravida. Amer. J. Obstet. Gynec., 123, 67-102.

17) Yamaguchi, R., Ushioda, E., Nishikawa, Y. \& Shintani, M. (1975) Uteroplacental blood flow in normal and prolonged pregnancies pursued with tracer mierospheres. Acta obstet. gynaec. jpn., 22, 175-181.

18) Yamaguchi, R., Takei, H., Ushioda, E., Nishikawa, Y., Moriyama, S.I., Ueda, S. \& Noda, T. (1976) Induction of SFD by microspheres blocking of placenta in rats and its influence on uteroplacental blood flow. Acta obstet. gynaec. jpn., 23, 83-86. 